\title{
CD147 expression was positively linked to aggressiveness and worse prognosis of gastric cancer: a meta and bioinformatics analysis
}

\author{
Hua-Chuan Zheng ${ }^{1}$ and Bao-Cheng Gong ${ }^{1}$ \\ ${ }^{1}$ Department of Experimental Oncology and Animal Center, Shengjing Hospital of China Medical University, Shenyang \\ 110004, China
}

Correspondence to: Hua-Chuan Zheng, email: zheng_huachuan@hotmail.com

Keywords: CD147, gastric cancer, meta analysis, bioinformatics analysis

Received: June 01, $2017 \quad$ Accepted: July 26, $2017 \quad$ Published: August 09, 2017

Copyright: Zheng et al. This is an open-access article distributed under the terms of the Creative Commons Attribution License 3.0 (CC BY 3.0), which permits unrestricted use, distribution, and reproduction in any medium, provided the original author and source are credited.

\section{ABSTRACT}

CD147 (also named as Basigin or EMMPRIN) might promote cancer invasion and metastasis by inducing MMP and VEGF synthesis in tumor microenvironment. We performed a systematic meta and bioinformatics analysis through multiple online databases up to March 14, 2017. Up-regulated CD147 expression was found in gastric cancer, compared with normal mucosa $(p<0.05)$. The male patients with gastric cancer showed higher CD147 expression than the female ones $(p<0.0001)$. CD147 expression was positively correlated with tumor size, depth of invasion, lymph node metastasis, TNM staging and unfavorable prognosis of gastric cancer $(p<0.05)$. At mRNA level, $C D 147$ expression was higher in intestinal-type and mixedtype gastric carcinomas than normal tissues $(p<0.05) . C D 147$ mRNA expression was negatively associated with histological grading and dedifferentiation of gastric cancer $(p<0.05)$. A higher CD147 mRNA expression was negatively correlated with overall and progression-free survival rates of all cancer patients, even stratified by clinicopathological features $(p<0.05)$. These findings indicated that CD147 expression might be employed as a potential marker to indicate gastric carcinogenesis and subsequent progression, even prognosis.

\section{INTRODUCTION}

CD147 (Basigin, M6 and tumor cell-derived collagenase stimulatory factor) was isolated from the surface of LX-1 lung carcinoma cells. Because it might increase cancer invasion by inducing MMP synthesis in neighboring fibroblasts, endothelial and cancer cells, including MT-MMP, MMP-1, MMP-2, and MMP-3, and the endogenous activators of MMP-2, CD147 is also named as EMMPRIN, which indicates its Extracellular Matrix Metalloproteinase Inducer activity [1-2]. It is a glycosylated cell surface transmembrane protein, and has core (approx $27 \mathrm{kDa}$ ), highly- (HG, 45-65 kDa) and lowly-glycosylated (LG, 32-44 kDa) forms [3]. Wang et al. [4] found that inhibition of $\mathrm{N}$-glycosylation increased the ubiquitination and degradation of CD147. F-Box protein FBXO22 could mediate the polyubiquitination and degradation of CD147 by interacting with CD147, and CD147 polyubiquitination by FBXO22 reversed cisplatin resistance of tumor cells [5].
Jia et al. [6] reported that CD147 deglycosylation downregulated MMP-11 expression and the adhesive capability of murine hepatocarcinoma cells. Our previous study showed that HG form was more expressed in ovarian cancer than normal ovary, and metastatic than primary cancers. HG-CD147 expression was positively correlated with FIGO staging and dedifferentiation of ovarian cancer [7]. Its two Ig-like domains in its extracellular portion induce MMP expression, while it is also cleaved by MMPs in tumor environments [8]. Serum or urine CD147 level was higher in transitional cell carcinoma and prostate cancer than healthy control $[9,10]$.

Reportedly, CD147 overexpression promoted cell invasion, epithelial-to-mesenchymal transition (EMT) via MAPK/ERK pathway in colorectal cancer [11]. CD147 was a target gene of Slug in TGF- $\beta \rightarrow$ PI3K/ $\mathrm{Akt} \rightarrow \mathrm{GSK} 3 \beta \rightarrow$ Snail $\rightarrow \mathrm{Slug} \rightarrow \mathrm{CD} 147$ signaling cascade, finally to cause EMT of hepatocellular carcinoma (HCC) cells [12]. Ru et al. [13] found that CD147 was involved in 
TGF- $\beta$-induced EMT and invasion of HCC cells. Hepatocytespecific CD147- knockout mice decreased the susceptibility to N-nitrosodiethylamine- induced tumorigenesis by suppressing TGF- $\beta 1-C D 147$ signaling and inhibiting dedifferentiation of hepatocytes during tumor progression [14]. Zhou et al. [15] demonstrated that CD147 mediated the chemoresistance of breast cancer via ABCG2, which affected the cellular localization and dimerization of CD147. Lv et al. [16] reported that CD147-postive cells from breast cancer tissues and cell lines possessed stem-cell-like features, including the ability of self-renewal in vitro, differentiation, and tumorigenic potential in vivo. These findings indicate that CD147 overexpression confers cancer cells more invasive and chemoresistant, which seem stemness.

CD147 has a broad tissue distribution, but its overexpression is also seen in breast cancers, $\mathrm{HCC}$, esophageal and cervical squamous cell carcinoma, genitourinary, gastric, colorectal, prostate and ovarian cancers $[1,2,17]$. Liang et al. [18] found that promoter hypomethylation of CD147 might result in the cancer-related overexpression of CD147 because more Sp1 protein bound to its promoter $[18,19]$. Wang et al. [20] showed that CD147 silencing inhibited cell proliferation, invasion and increased chemosensitivity to cisplatin in SGC7901 cells in vitro. In our previous work, CD147 expression was found to positively correlate with tumor size, depth of invasion, lymphatic invasion, expression of ki-67, MMP-2, MMP-9 and VEGF, angiogenesis and unfavorable prognosis of gastric cancer [21]. Here, we performed a meta and bioinformatics analysis to confirm the clinicopathological and prognostic significances of CD147 expression at both protein and mRNA levels.

\section{RESULTS}

\section{Characteristics of eligible studies}

Figure 1 is a flow diagram of paper selection for our meta-analysis. As shown in Table 1, a total of 22 articles on the relationship between CD147 expression and cancer risk, clinicopathological or prognostic parameters of gastric cancer were retrieved for our meta-analysis by immunohistochemistry in PubMed, Web of Science, BIOSIS, SciFinder and CNKI. Only 20 articles contained the samples of normal gastric mucosa [21-40]. There appeared the comparison between CD147 expression and clinicopathological characteristics of gastric cancer in 22 pieces of paper, including sex, depth of invasion, lymph node metastasis, TNM staging and Lauren's classification [21-42]. Finally, we discussed the prognostic significance of CD147 expression in 4 articles [21, 24, 27, 32].

\section{Association between CD147 expression and cancer susceptibility of gastric mucosa}

We analyzed the association between CD147 expression and cancer susceptibility of gastric normal mucosa in 20 studies with 2496 cancers and 1013 controls. As a result, we found up-regulated CD147 expression in gastric cancer, compared with normal mucosa (Figure 2A, $p=0.002)$.

\section{Association between CD147 expression and clinicopathological parameters of gastric cancer}

As shown in Figure 2B, there was no difference in CD147 expression between younger ( $<60$ years) and elder $(\geqq 60$ years) patients with gastric cancer $(p>0.05)$. The male patients with gastric cancer showed higher CD147 expression than the female ones (Figure 2C, $p<0.0001)$. The large cancers $(\geqq 4 \mathrm{~cm})$ displayed more CD147 expression than the small ones $(<4 \mathrm{~cm}$, Figure 2D, $p<0.001$ ). A lower CD147 expression was detected in Tis-2 than T3-4 gastric cancers (Figure 2E, $p<0.00001)$. CD147 expression was positively related to lymph node metastasis of gastric cancer (Figure 2F, $p<0.00001)$. Gastric cancers with stage III-IV showed CD147 overexpression, compared with ones with stage I-II (Figure 2G, $p<0.00001$ ). There was no difference in CD147 protein expression between intestinal-type than diffuse-type carcinomas (Figure $2 \mathrm{H}, p>0.05$ ).

\section{Association between CD147 expression and survival rate of gastric cancer}

As indicated in Figure 2I, the pooled result from 4 studies demonstrated a significant association between CD147 expression and unfavorable overall survival in patients with gastric cancer $(\mathrm{HR}=0.79,95 \% \mathrm{CI}: 0.65-0.96$, $p<0.05)$. Results showed that CD147 overexpression had an unfavorable prognostic value in gastric cancer patients.

\section{Publication bias}

The heterogeneity test was performed as shown in Figure 3. Sensitivity analysis was used to evaluate individual study's influence on the pooled results by deleting one single study each time from pooled analysis. The T-staging result of CD147 expression in Gao's study had a significant effect on the pooled OR. When this study was excluded, the heterogeneity test was significantly reduced (data not shown).

\section{The clinicopathological and prognostic significances of CD147 mRNA expression in gastric cancers}

Then, we used DErrico's dataset to perform bioinformatics analysis and found that CD147 mRNA expression was higher in intestinal-type and diffuse-type gastric carcinomas than normal tissues (Figure 4A, $p<0.05$ ). According to TCGA data, $C D 147$ mRNA expression was higher in Grade 1-2 than Grade 3 carcinomas (Figure 4B, 
Table 1: Main characteristics of eligible studies

\begin{tabular}{|c|c|c|c|c|c|c|c|c|c|}
\hline First author & Year & Country & Ethnicity & AS & Cases & Control & Risk to cancer & Outcome & Quality \\
\hline Zheng HC & 2006 & Japan & Asian & NovoCastra & 234 & 28 & Up & Negative & 9 \\
\hline Pinheiro C & 2009 & Brazil & Brazil & Zymed & 160 & 66 & --- & & 8 \\
\hline Chu D & 2014 & China & Asian & NovoCastra & 223 & 223 & Up & Negative & 9 \\
\hline Huang L & 2015 & China & Asian & Zymed & 74 & 20 & Up & Negative & 9 \\
\hline Chen ZQ & 2005 & China & Asian & Zymed & 40 & 20 & Up & & 9 \\
\hline Zheng X & 2005 & China & Asian & Zhongshan & 123 & & & & 8 \\
\hline Huang Y & 2007 & China & Asian & Maxim & 58 & 20 & Up & & 7 \\
\hline Gao J & 2009 & China & Asian & Santa Cruz & 70 & 5 & Up & & 8 \\
\hline $\mathrm{He} \mathrm{C}$ & 2009 & China & Asian & Maxim & 50 & 30 & Up & Negative & 8 \\
\hline Wu Q & 2010 & China & Asian & Zhongshan & 161 & 40 & Up & & 8 \\
\hline $\mathrm{Xu} \mathrm{JM}$ & 2010 & China & Asian & Santa Cruz & 65 & 65 & Up & & 7 \\
\hline Fan RG & 2010 & China & Asian & Zhongshan & 120 & 120 & Up & & 7 \\
\hline Liu XL & 2012 & China & Asian & Santa Cruz & 199 & 21 & Up & & 8 \\
\hline Liu L & 2012 & China & Asian & Meinuoke & 441 & 100 & Up & & 7 \\
\hline Miao J & 2012 & China & Asian & Zhongshan & 178 & 10 & Up & & 8 \\
\hline Chen $\mathrm{T}$ & 2013 & China & Asian & Santa Cruz & 126 & 40 & Up & & 7 \\
\hline Zhang LT & 2013 & China & Asian & Santa Cruz & 70 & 20 & Up & & 8 \\
\hline Zhou MX & 2013 & China & Asian & Maxin & 70 & 5 & Up & & 7 \\
\hline Li B & 2016 & China & Asian & Baijing & 54 & 60 & Up & & 8 \\
\hline Gao WH & 2016 & China & Asian & Zhongshan & 46 & 40 & Up & Negative & 8 \\
\hline Zhou JF & 2016 & China & Asian & Baijing & 40 & 80 & Up & & 8 \\
\hline
\end{tabular}

$p<0.05)$. It was more expressed in intestinal-type than diffuse-type carcinomas (Figure 4C, $p<0.05$ ).

According to Kaplan-Meier plotter, we found that a higher $C D 147$ mRNA expression was negatively correlated with overall and progression-free survival rates of all cancer patients (Figure 4D and 4E, $p<0.05$ ). As shown in Table 2, it was the same for the patients with any gender, stage II-IV, T2-3, N1-3, M0, surgery alone, 5-FU-based adjuvant, intestinal-type and diffuse-type, Her2-positive and -negative carcinomas $(p<0.05)$.

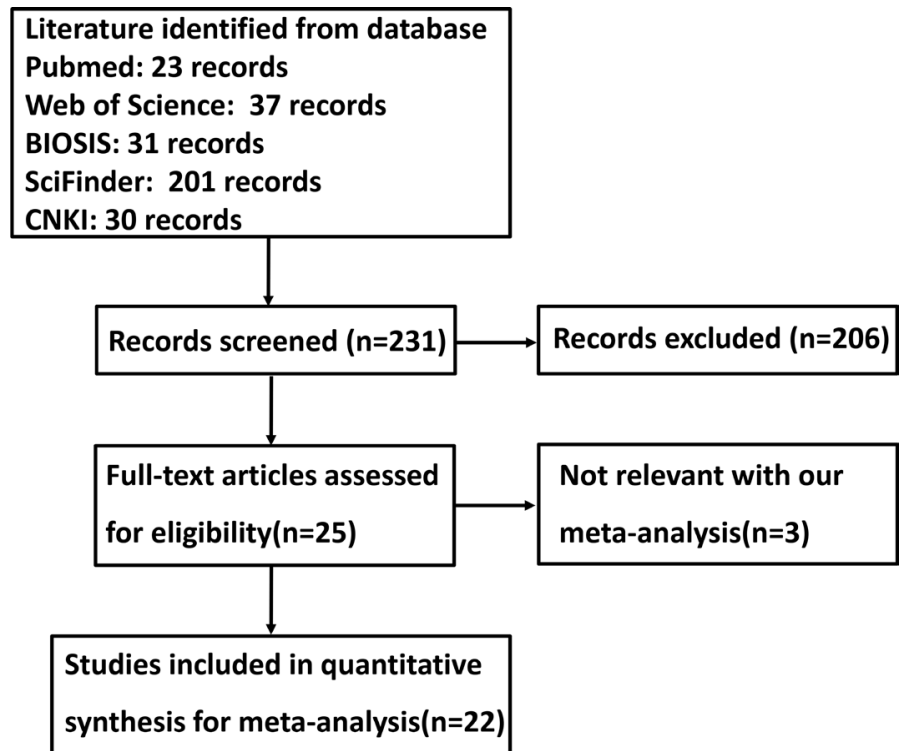

Figure 1: Flow diagram of the selection process in this meta-analysis. 
A

Normal Cancer

Odds Ratio

Odds Ratio

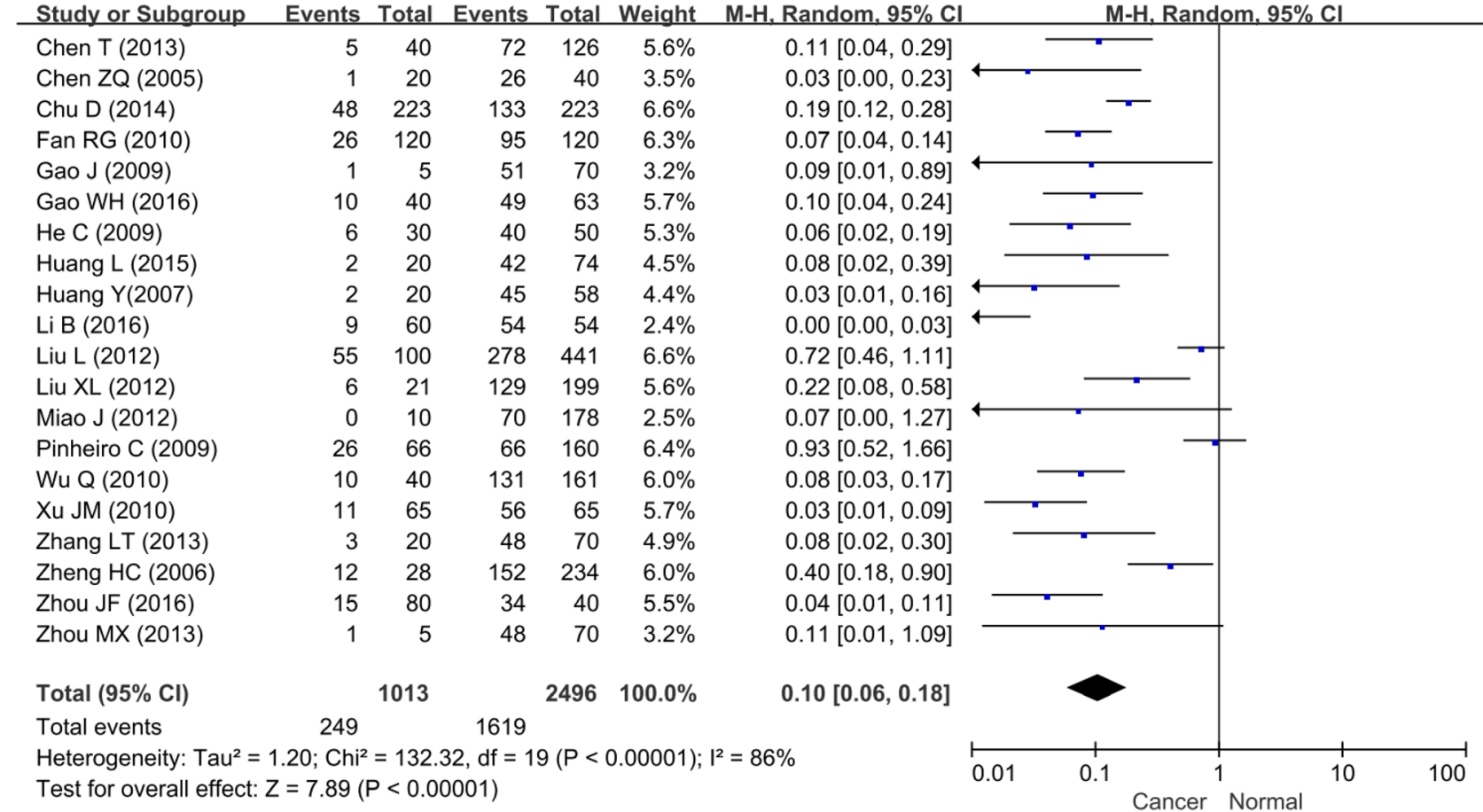

\begin{tabular}{|c|c|c|c|c|c|c|}
\hline \multirow{2}{*}{ B Study or Subgroup } & \multirow{2}{*}{\multicolumn{2}{|c|}{$<60$ years }} & \multirow{2}{*}{\multicolumn{2}{|c|}{$\begin{array}{l}\geqq 60 \text { years } \\
\text { Events Total }\end{array}$}} & \multirow{2}{*}{\multicolumn{2}{|c|}{$\begin{array}{cc}\text { Odds Ratio } \\
\text { Weight } \\
\text { M-H. Fixed. 95\% Cl }\end{array}$}} \\
\hline & & & & & & \\
\hline Chen T (2013) & 41 & 73 & 31 & 53 & $15.9 \%$ & $0.91[0.44,1.86]$ \\
\hline Chu D (2014) & 73 & 131 & 60 & 92 & $31.5 \%$ & $0.67[0.39,1.16]$ \\
\hline Gao J (2009) & 26 & 38 & 25 & 32 & $8.6 \%$ & $0.61[0.21,1.79]$ \\
\hline Gao WH (2016) & 20 & 28 & 29 & 35 & $7.4 \%$ & $0.52[0.16,1.72]$ \\
\hline & 75 & 98 & 65 & 80 & $16.9 \%$ & 1.56] \\
\hline Wu Q (2010) & 64 & 75 & 67 & 86 & $9.2 \%$ & $1.65[0.73,3.74]$ \\
\hline Zhou JF (2016) & 20 & 23 & 14 & 17 & $2.1 \%$ & $1.43[0.25,8.14]$ \\
\hline Zhou MX (2013) & 26 & 39 & 22 & 31 & $8.2 \%$ & $0.82[0.29,2.27]$ \\
\hline & & 505 & & 426 & $100.0 \%$ & $0.82[0.62,1.10]$ \\
\hline Total $\mathrm{e}$ & 345 & & 313 & & & \\
\hline
\end{tabular}

Heterogeneity: $\mathrm{Chi}^{2}=4.70, \mathrm{df}=7(\mathrm{P}=0.70) ; \mathrm{I}^{2}=0 \%$

Test for overall effect: $Z=1.29(P=0.20)$

C

Male Female

Odds Ratio

Odds Ratio

M-H. Fixed. $95 \% \mathrm{Cl}$

Cl

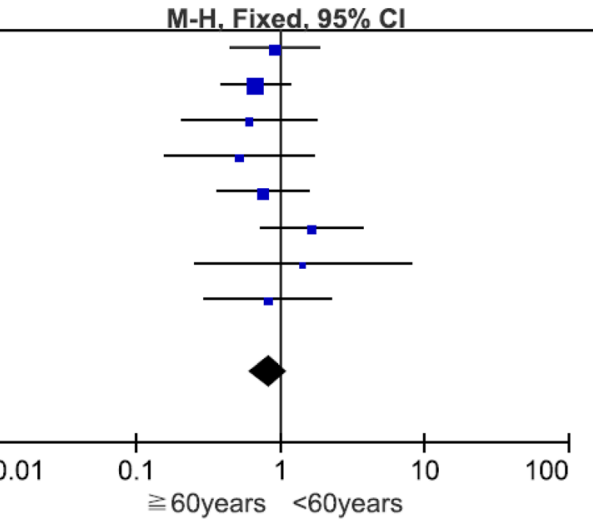

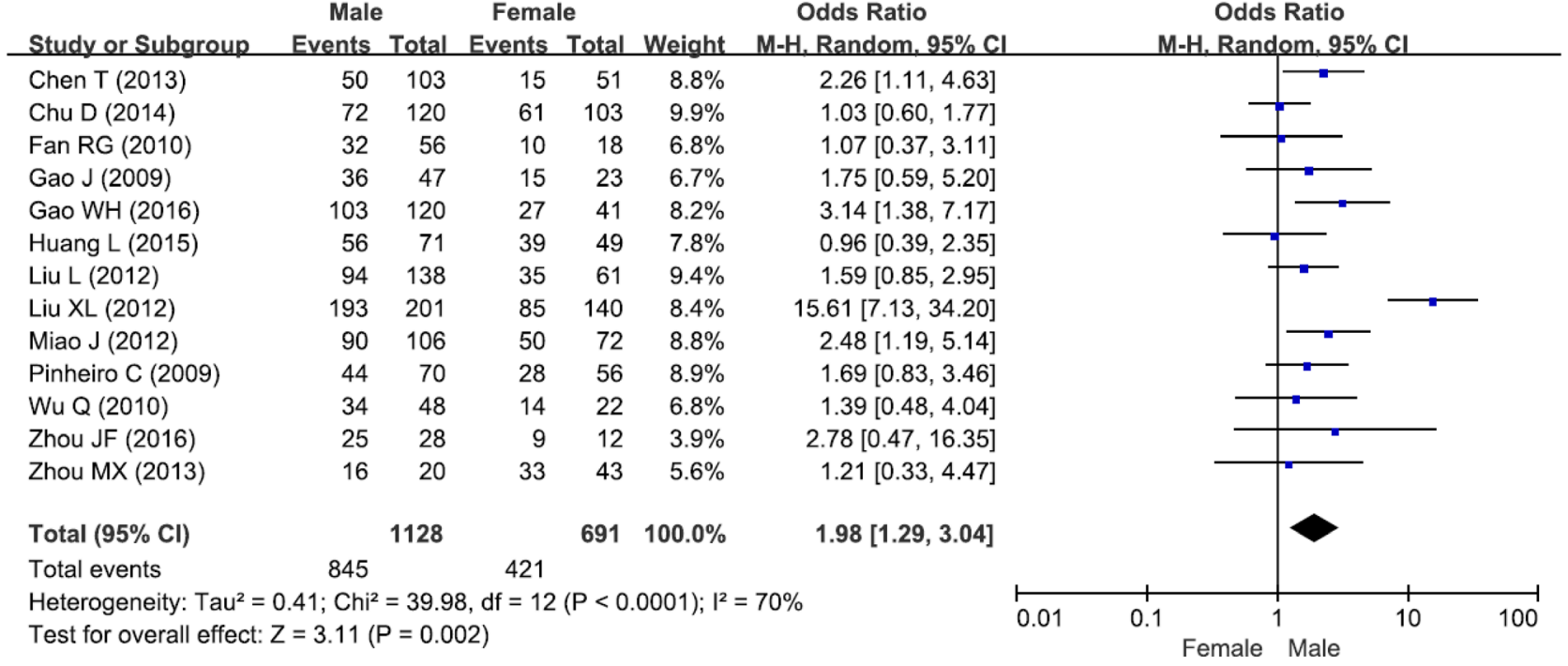




\begin{tabular}{|c|c|c|c|c|c|c|c|c|c|c|c|c|}
\hline D_ & Study or Subgroup & \multicolumn{2}{|c|}{$<4 \mathrm{~cm}$} & \multicolumn{2}{|c|}{$\geqq 4 \mathrm{~cm}$} & \multicolumn{2}{|r|}{$\begin{array}{l}\text { Odds Ratio } \\
\text { M-H. Fixed. } 95 \% \mathrm{Cl}\end{array}$} & \multicolumn{5}{|c|}{$\begin{array}{c}\text { Odds Ratio } \\
\text { M-H, Fixed, } 95 \% \mathrm{Cl}\end{array}$} \\
\hline & Liu L (2012) & 91 & 168 & 187 & 273 & $54.2 \%$ & $0.54[0.37,0.81]$ & & & & & \\
\hline & Pinheiro C (2009) & 19 & 60 & 44 & 93 & $19.6 \%$ & $0.52[0.26,1.02]$ & & & & & \\
\hline & Zheng HC (2006) & 66 & 110 & 84 & 124 & $26.2 \%$ & $0.71[0.42,1.22]$ & & & & & \\
\hline & Total $(95 \% \mathrm{Cl})$ & & 338 & & 490 & $100.0 \%$ & $0.58[0.44,0.78]$ & & & & & \\
\hline & Total events & 176 & & 315 & & & & & & & & \\
\hline & $\begin{array}{l}\text { Heterogeneity: } \mathrm{Chi}^{2}= \\
\text { Test for overall effect }\end{array}$ & $\begin{array}{l}0.80, d f=2 \\
Z=3.67(P\end{array}$ & $\begin{array}{l}2(P=0 \\
P=0.00\end{array}$ & $\begin{array}{l}0.67) ;\left.\right|^{2}= \\
002)\end{array}$ & $=0 \%$ & & & 0.01 & 0.1 & $\geqq 4 \mathrm{~cm}^{1}$ & $<4 \mathrm{~cm} \quad 10$ & 100 \\
\hline E & Study or Subgroup & $\begin{array}{c}\text { T0-T2 } \\
\text { Events } \\
\end{array}$ & Total & $\begin{array}{c}\text { T3-T4 } \\
\text { Events }\end{array}$ & 4 Total & Weight & $\begin{array}{c}\text { Odds Ratio } \\
\text { M-H, Random, } 95 \% \mathrm{Cl}\end{array}$ & & & $\begin{array}{r}\text { Odds } \\
\text { 1-H, Rando } \\
\end{array}$ & $\begin{array}{l}\text { Ratio } \\
\text { om. } 95 \% \mathrm{Cl}\end{array}$ & \\
\hline & Chu D (2014) & 59 & 109 & 74 & 114 & $11.9 \%$ & $0.64[0.37,1.09]$ & & & & & \\
\hline & Fan RG (2010) & 19 & 29 & 76 & 81 & $5.9 \%$ & $0.13[0.04,0.41]$ & & & & & \\
\hline & Gao J (2009) & 19 & 22 & 32 & 48 & $4.9 \%$ & $3.17[0.81,12.31]$ & & & & & \\
\hline & Gao WH (2016) & 14 & 23 & 35 & 40 & $5.5 \%$ & $0.22[0.06,0.78]$ & & & & & \\
\hline & $\mathrm{He} \mathrm{C} \mathrm{(2010)}$ & 10 & 19 & 30 & 31 & $2.3 \%$ & $0.04[0.00,0.33]$ & & & & & \\
\hline & Huang Y (2007) & 20 & 30 & 24 & 28 & $5.2 \%$ & $0.33[0.09,1.23]$ & & & & & \\
\hline & Liu L (2012) & 58 & 114 & 220 & 327 & $13.1 \%$ & $0.50[0.33,0.78]$ & & & & & \\
\hline & Liu XL (2012) & 33 & 64 & 96 & 135 & $11.0 \%$ & $0.43[0.23,0.80]$ & & & & & \\
\hline & Miao J (2012) & 31 & 48 & 78 & 92 & $8.8 \%$ & $0.33[0.14,0.74]$ & & & & & \\
\hline & Pinheiro C (2009) & 60 & 147 & 4 & 6 & $3.4 \%$ & $0.34[0.06,1.94]$ & & & & & \\
\hline & Wu Q (2010) & 45 & 64 & 86 & 97 & $8.7 \%$ & $0.30[0.13,0.69]$ & & & & & \\
\hline & Xu JM (2010) & 15 & 22 & 41 & 43 & $3.6 \%$ & $0.10[0.02,0.56]$ & & & & & \\
\hline & Zhang LT (2013) & 11 & 32 & 15 & 28 & $6.9 \%$ & $0.45[0.16,1.29]$ & & & & & \\
\hline & Zhou JF (2016) & 10 & 15 & 24 & 25 & $2.2 \%$ & $0.08[0.01,0.81]$ & & & & & \\
\hline & Zhou MX (2013) & 13 & 25 & 36 & 45 & $6.7 \%$ & $0.27[0.09,0.79]$ & & & & & \\
\hline & Total $(95 \% \mathrm{Cl})$ & & 763 & & 1140 & $100.0 \%$ & $0.36[0.25,0.51]$ & & & & & \\
\hline & Total events & 417 & & 871 & & & & & & & & \\
\hline & $\begin{array}{l}\text { Heterogeneity: } \mathrm{Tau}^{2} \\
\text { Test for overall effect }\end{array}$ & $\begin{array}{l}0.21 ; \mathrm{Chi}^{2} \\
\mathrm{Z}=5.61(\mathrm{P}\end{array}$ & $\begin{array}{l}=27.60 \\
><0.00\end{array}$ & $\begin{array}{l}0, \mathrm{df}=14 \\
0001)\end{array}$ & $(P=0$. & $.02) ; \mathbf{I}^{2}=4$ & & 0.01 & 0.1 & 1 & 10 & 100 \\
\hline
\end{tabular}

(1)

\begin{tabular}{ccccc} 
& LN- & LN+ & Odds Ratio & Odds Ratio \\
Study or Subgroup & Events Total Events Total Weight & M-H, Random, $95 \% \mathrm{Cl}$ & M-H, Random, $95 \% \mathrm{Cl}$ \\
\hline
\end{tabular} Chen T (2013) Chen ZQ (2005)

Chu D (2014)

Fan RG (2010)

Gao J (2009)

Gao WH (2016)

$\mathrm{He} \mathrm{C}$ (2009)

Huang L (2015)

Huang $Y(2007)$

Liu L (2012)

Liu XL (2012)

Miao J (2012)

Pinheiro C (2009)

Wu Q (2010)

Xu JM (2010)

Zhang LT (2013)

Zheng HC (2006)

Zhou JF (2016)

Zhou MX (2013)

vents To

Total $(95 \% \mathrm{Cl})$

Total events

$\begin{array}{rrrrr}16 & 38 & 56 & 88 & 6.4 \% \\ 15 & 26 & 87 & 97 & 4.9 \% \\ 32 & 97 & 101 & 126 & 7.7 \% \\ 27 & 46 & 68 & 74 & 4.8 \% \\ 21 & 34 & 30 & 36 & 4.4 \% \\ 13 & 22 & 36 & 41 & 3.7 \% \\ 25 & 34 & 15 & 16 & 1.6 \% \\ 14 & 36 & 28 & 38 & 5.0 \% \\ 16 & 27 & 29 & 31 & 2.6 \% \\ 78 & 152 & 200 & 289 & 9.5 \% \\ 51 & 92 & 78 & 107 & 7.9 \% \\ 22 & 91 & 48 & 87 & 7.5 \% \\ 22 & 74 & 42 & 76 & 7.2 \% \\ 41 & 58 & 90 & 103 & 6.2 \% \\ 17 & 24 & 43 & 45 & 2.5 \% \\ 6 & 27 & 21 & 43 & 4.5 \% \\ 82 & 130 & 70 & 104 & 8.3 \% \\ 15 & 21 & 19 & 19 & 0.9 \% \\ 20 & 36 & 28 & 34 & 4.4 \% \\ & & & & \\ & 1065 & & 1454 & 100.0 \% \\ 533 & & 1089 & & \end{array}$

$0.42[0.19,0.90]$

$0.16[0.06,0.43]$

$0.12[0.07,0.22]$

$0.13[0.05,0.35]$

$0.32[0.11,0.99]$

$0.20[0.06,0.71]$

$0.19[0.02,1.61]$

$0.23[0.08,0.61]$

$0.10[0.02,0.51]$

$0.47[0.31,0.70]$

$0.46[0.26,0.84]$

$0.26[0.14,0.49]$

$0.34[0.17,0.67]$

$0.35[0.15,0.78]$

$0.11[0.02,0.60]$

$0.30[0.10,0.89]$

$0.83[0.48,1.43]$

$0.06[0.00,1.17]$

$0.27[0.09,0.80]$

$0.28[0.21,0.38]$

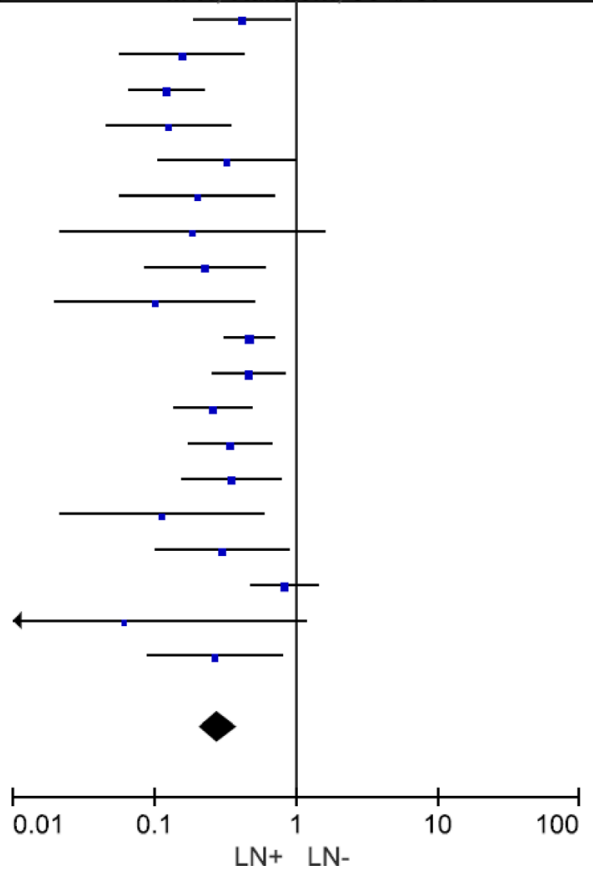

Test for overall effect: $Z=8.39(P<0.00001)$ 

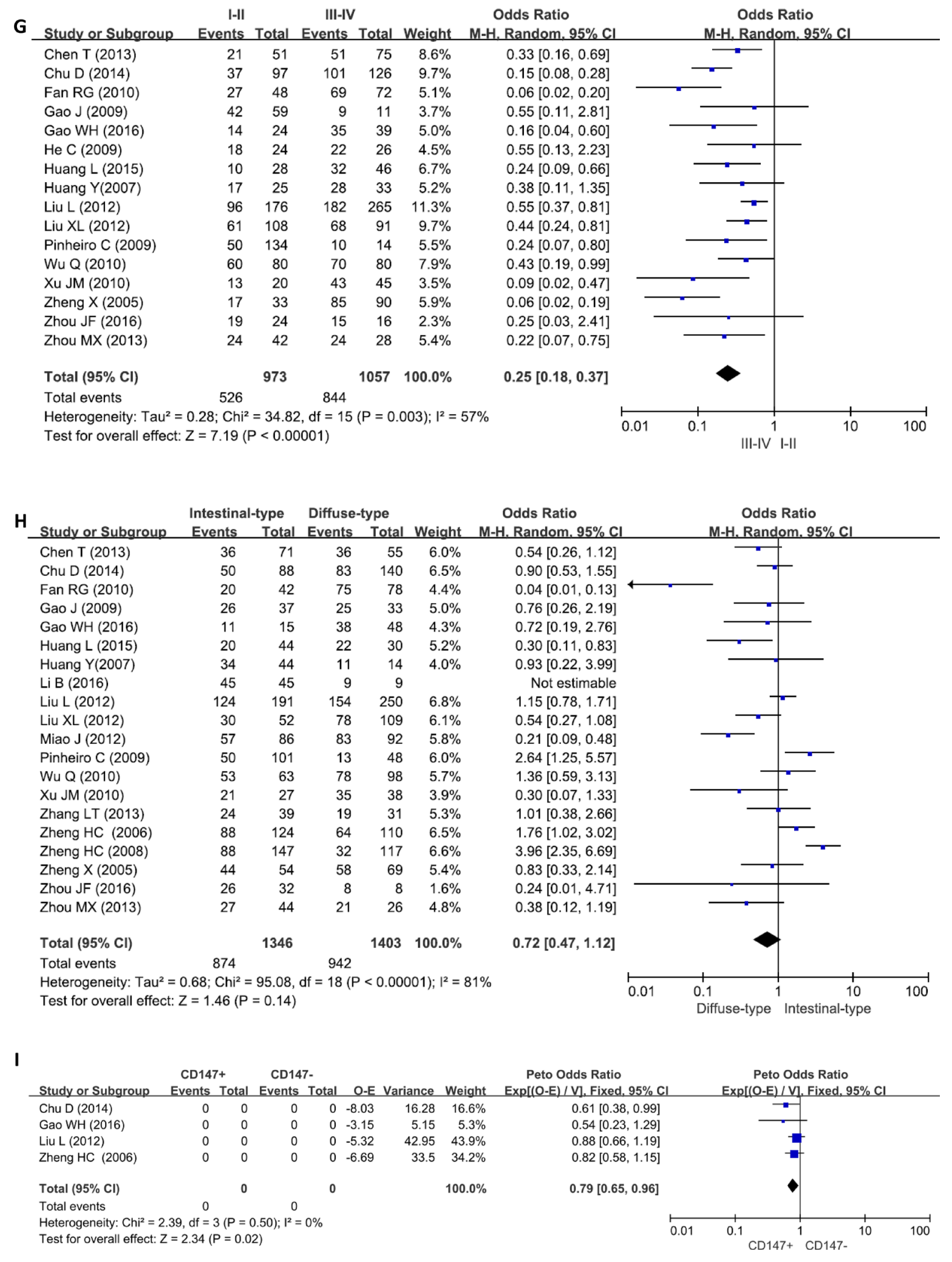

Figure 2: Forest plot for the relationship between CD147 expression and clinicopatholoiocal parameters of gastric cancer. (A) gastric carcinogenesis (cancer vs normal mucosa); (B) correlation between age and CD147 expression ( $\geqq 60$ years vs $<60$ years) ; (C) correlation between sex and CD147 expression (female vs male); (D) correlation between tumor size and CD147 expression ( $\geqq 4 \mathrm{~cm} v s<4 \mathrm{~cm}$ ); (E) correlation between depth of invasion and CD147 expression (T3-4 vs Tis-2); (F) correlation between lymph node metastasis (LN) and CD147 expression (LN+ vs LN-); (G) correlation between TNM staging and CD147 expression (stage III-IV vs 0-II); (H) correlation between differentiation and CD147 (diffuse-type vs intestinal-type). (I) correlation between survival rate and CD147 expression (CD147 - vs CD147 +). 


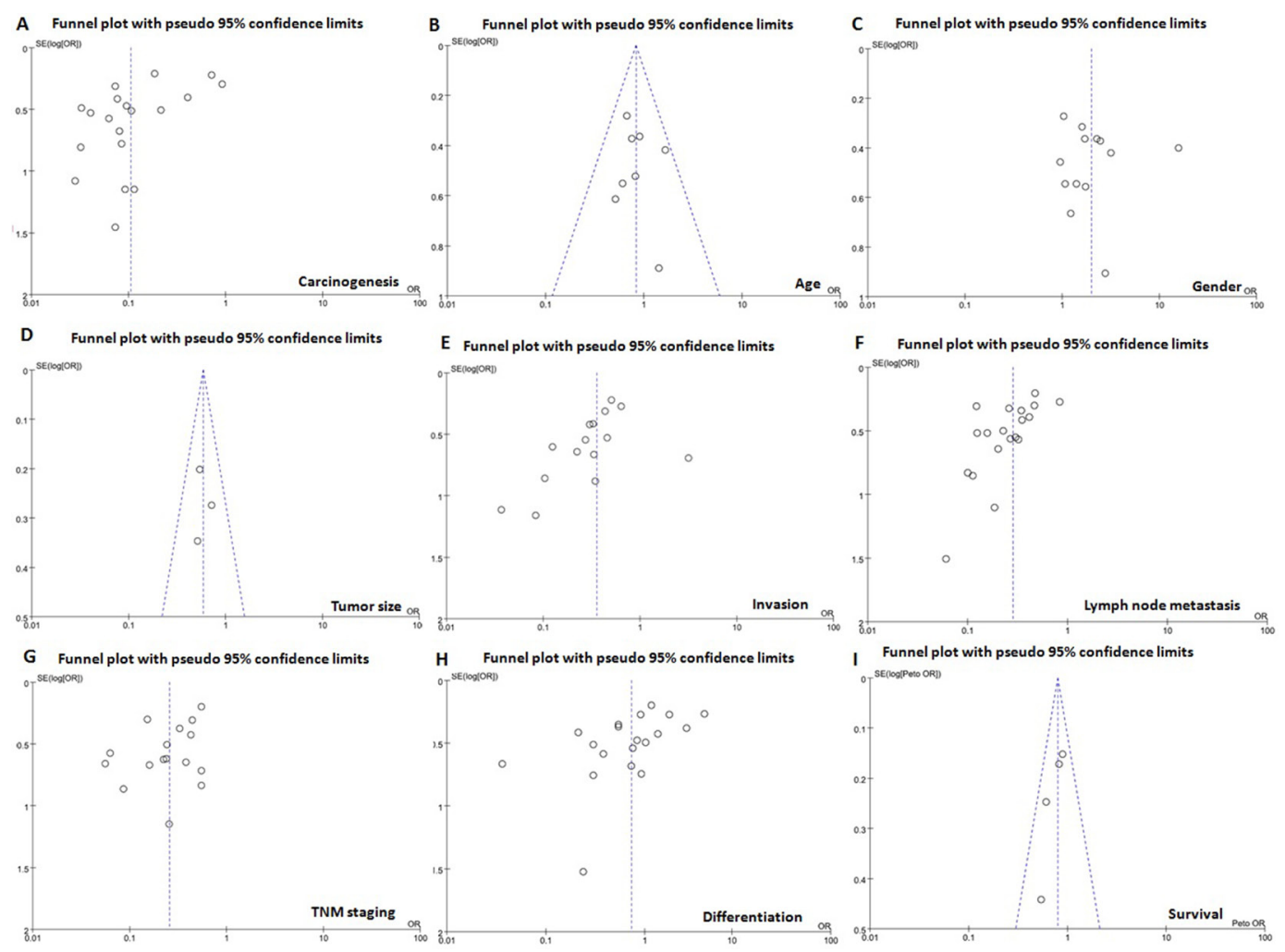

Figure 3: Funnel plot for publication bias test between CD147 expression and gastric carcinogenesis or progression. The bias was analyzed about risk degrees of CD147 expression in gastric mucosa (A) for gastric carcinogenesis. Additionally, it was tested between CD147 expression and clinicopathlogical features of gastric cancer, including age (B), gender (C), tumor size (D), depth of invasion $(\mathbf{E})$, lymph node metastasis $(\mathbf{F})$, TNM staging $(\mathbf{G})$, and differentiation $(\mathbf{H})$ and prognosis $(\mathbf{I})$.
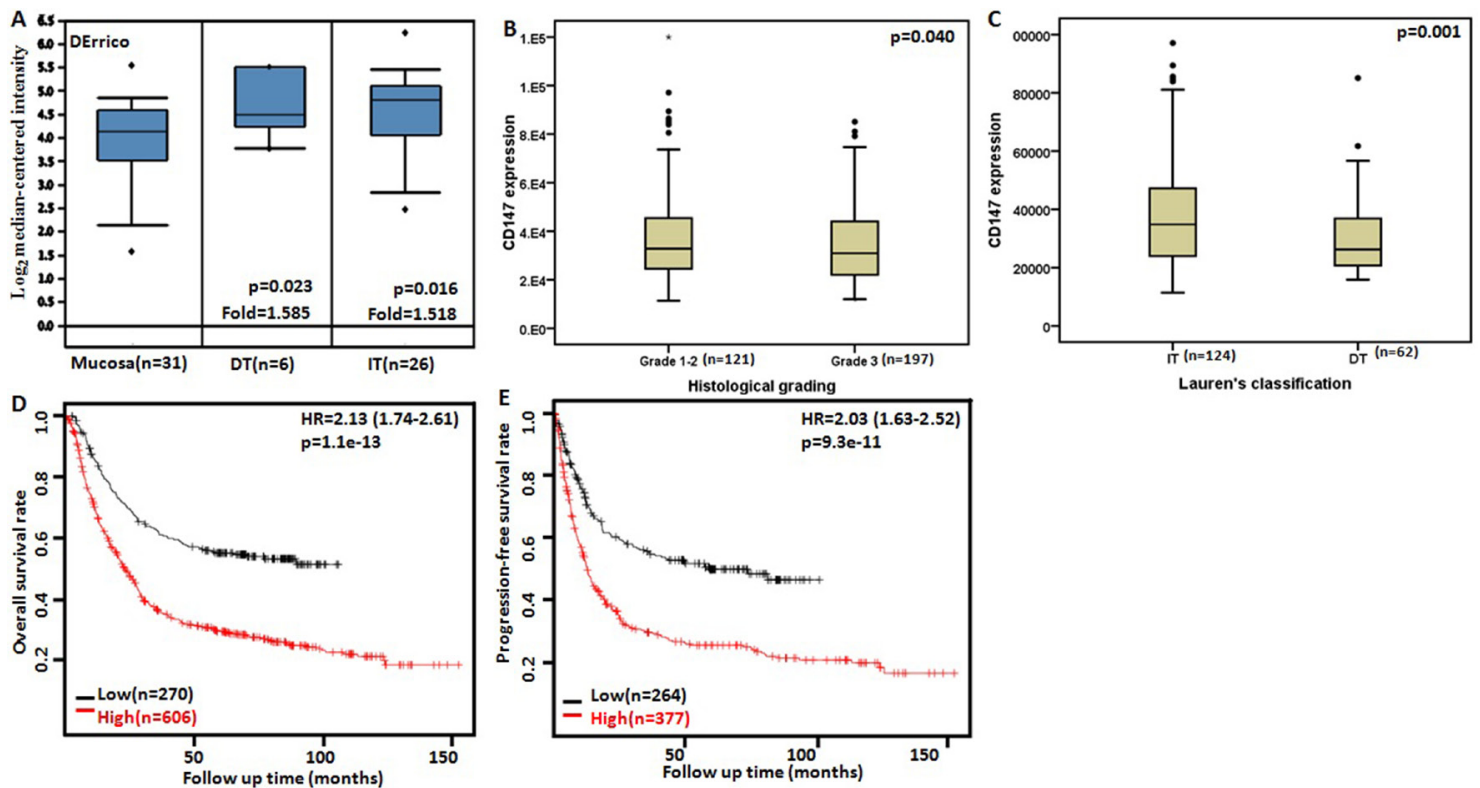

Figure 4: The clinicopathological significance of $C D 147$ mRNA expression in gastric cancer. Derrico datasets were employed for bioinformatics analysis to analyze $C D 147$ mRNA expression during gastric carcinogenesis. A higher $C D 147$ expression was detectable in gastric cancer than that in normal gastric mucosa, even stratified into intestinal-type (IT) and diffuse-type (DT) carcinomas by Lauren's classification (A) $p<0.05$ ). TCGA database shows that CD147 mRNA expression was histologically more expressed in high-grade carcinomas than low-grade ones (B) $p<0.05$ ). Additionally, CD147 mRNA over expression was observed in IT carcinomas in comparison to DT ones $(\mathbf{C}) p<0.05)$. According to the data from KM plotter, CD147 mRNA expression was positively related to both overall (D) and progression-free (E) survival rates of the patients with gastric cancer. HR, hazard ratio. 
Table 2: The prognostic significance of $C D 147$ mRNA in gastric cancer

\begin{tabular}{|c|c|c|c|c|}
\hline \multirow{2}{*}{ Clinicopathological features } & \multicolumn{2}{|c|}{ Overall survival } & \multicolumn{2}{|c|}{ Progression-free survival } \\
\hline & Hazard ratio & $p$ & Hazard ratio & $p$ \\
\hline \multicolumn{5}{|l|}{ Sex } \\
\hline Female & $1.88(1.29-2.75)$ & $8 \mathrm{e}-04$ & $1.62(1.1-2.4)$ & 0.014 \\
\hline Male & $2.32(1.81-2.99)$ & $1.4 \mathrm{e}-11$ & $2.31(1.77-3.01)$ & $2.9 \mathrm{e}-10$ \\
\hline \multicolumn{5}{|l|}{ TNM staging } \\
\hline I & $3.15(0.87-11.42)$ & 0.066 & $2.06(0.53-7.95)$ & 0.29 \\
\hline II & $2.22(1.2-4.12)$ & 0.0091 & $2.26(1.21-4.22)$ & 0.0084 \\
\hline III & $2.2(1.54-3.13)$ & $8 e-06$ & $1.9(1.3-2.77)$ & 0.00068 \\
\hline IV & $2.55(1.03-6.35)$ & 0.037 & $2.66(1.17-6.04)$ & 0.015 \\
\hline \multicolumn{5}{|l|}{$\mathrm{T}$} \\
\hline 2 & $1.79(1.16-2.75)$ & 0.0072 & $1.74(1.15-2.62)$ & 0.0081 \\
\hline 3 & $1.83(1.29-2.59)$ & 0.00057 & $1.5(1.07-2.1)$ & 0.018 \\
\hline 4 & $2.55(1.03-6.35)$ & 0.037 & $2.66(1.17-6.04)$ & 0.015 \\
\hline \multicolumn{5}{|l|}{$\mathrm{N}$} \\
\hline 0 & $1.61(0.63-4.15)$ & 0.32 & $1.5(0.59-3.84)$ & 0.39 \\
\hline $1-3$ & $2.08(1.6-2.71)$ & $2.7 \mathrm{e}-08$ & $1.82(1.41-2.34)$ & $3.1 \mathrm{e}-06$ \\
\hline 1 & $2.58(1.69-3.93)$ & $4.9 \mathrm{e}-06$ & $2.46(1.61-3.75)$ & $1.5 \mathrm{e}-05$ \\
\hline 2 & $3.13(1.97-4.98)$ & $4.1 \mathrm{e}^{-07}$ & $2.5(1.61-3.89)$ & $2.5 \mathrm{e}-05$ \\
\hline 3 & $0.52(0.29-0.93)$ & 0.024 & $0.52(0.29-0.93)$ & 0.026 \\
\hline \multicolumn{5}{|l|}{ M } \\
\hline 0 & $1.93(1.44-2.57)$ & $5.7 \mathrm{e}-06$ & $1.65(1.26-2.17)$ & 0.00026 \\
\hline 1 & $2.66(1.41-5.02)$ & 0.0017 & $1.64(0.88-3.06)$ & 0.12 \\
\hline \multicolumn{5}{|l|}{ Perforation } \\
\hline- & $1.43(0.96-2.14)$ & 0.076 & $1.36(0.92-1.99)$ & 0.12 \\
\hline \multicolumn{5}{|l|}{ Treatment } \\
\hline Surgery alone & $1.38(1.02-1.87)$ & 0.039 & $0.73(0.54-1)$ & 0.046 \\
\hline 5-FU-based adjuvant & $0.53(0.36-0.78)$ & 0.00097 & $0.51(0.34-0.77)$ & 0.00096 \\
\hline Other adjuvant & $0.34(0.14-0.84)$ & 0.014 & $0.45(0.2-1.05)$ & 0.059 \\
\hline \multicolumn{5}{|l|}{ Differentiation } \\
\hline Well-differentiated & $0.36(0.15-0.86)$ & 0.017 & - & - \\
\hline Moderately-differentiated & $1.45(0.76-2.78)$ & 0.26 & $0.72(0.38-1.36)$ & 0.31 \\
\hline Poorly-differentiated & $1.34(0.9-2)$ & 0.15 & $1.59(0.99-2.55)$ & 0.051 \\
\hline \multicolumn{5}{|l|}{ Lauren's classification } \\
\hline Intestinal-type & $2.76(1.96-3.9)$ & $1.5 \mathrm{e}-09$ & $2.32(1.58-3.41)$ & $1 \mathrm{e}-05$ \\
\hline Diffuse-type & $1.5(1.04-2.15)$ & 0.028 & $1.55(1.08-2.22)$ & 0.017 \\
\hline Mixed-type & $1.85(0.65-5.24)$ & 0.24 & $0.4(0.13-1.2)$ & 0.091 \\
\hline \multicolumn{5}{|l|}{ Her2 positivity } \\
\hline- & $1.91(1.5-2.43)$ & $1.1 \mathrm{e}^{-07}$ & $1.82(1.4-2.37)$ & $6.3 \mathrm{e}-06$ \\
\hline+ & $1.5(1.1-2.05)$ & 0.011 & $1.85(1.23-2.77)$ & 0.0027 \\
\hline
\end{tabular}

\section{DISCUSSION}

Invasion and metastasis are key and characteristic events in the aggressive biology of cancer, and become major obstacles to the treatment of malignancies. Various evidences showed that CD147 might enhance the migration and metastasis of cancer via Annexin A2/ DOCK3- $\beta$-catenin- WAVE2, EGFR-src-Rac1-pSTAT3DOCK8, integrin-FAK-PI3K/PIP3-Rac1-WAVE2 and FAK- PI3K/PIP3-Rac1-WAVE2 pathways [43-46]. Sidhu et al. [47] reported that a higher CD147 expression in lung cancer epithelial cells activated $\beta$-catenin signaling 
pathway, and CD147 silencing inhibited $\beta$-catenin signaling, cell migration, proliferation, anchorageindependent growth and tumor growth in a mouse tumor xenograft model. Besides, CD147 enhanced tumor growth of melanoma by up-regulating GLUT-1 level via activating PI3K/Akt signaling and increasing glucose uptake, stimulated hepatoma cells escaping from immune surveillance of $\mathrm{T}$ cells by interaction with Cyclophilin A, reprogrammed fatty acid metabolism in HCC cells through Akt/mTOR/SREBP1c and p38/PPAR $\alpha$ pathways, promoted autophagy through $\mathrm{PI} 3 \mathrm{~K} / \mathrm{Akt} / \mathrm{mTOR}$ pathway in human prostate cancer cells, and chemosensitivity in head and neck squamous carcinoma cells by activating MAPK/ ERK pathway [48-52].

In the present study, CD147 overexpression was found in gastric cancer, and positively correlated with tumor size, depth of invasion, lymph node metastasis, or TNM staging, in line with the results form bladder urothelial carcinoma, laryngeal carcinoma, thyroid cancer, colorectal cancer, ovarian cancer, glioma, and tongue squamous cell carcinoma [53-59]. These findings suggested that its up-regulation contributed to carcinogenesis and subsequent progression, and might be employed as a good marker for carcinogenesis and aggressive behaviors. A higher CD147 mRNA in intestinal-type or G1-2 carcinoma was noted than in diffuse-type or G3 ones respectively, indicating that its distinct expression might underlie the molecular basis of differentiation in gastric cancer. In contrast, Zhu et al. [60] found that higher CD147 expression was correlated with the poor tumor differentiation of HCC. However, a high heterogeneity was seen in the correlation of CD147 expression with carcinogenesis, invasion, lymph node metastasis, TNM staging and differentiation of gastric cancer, which might be due to the various anti-CD147 antibody sources, different populations, sample selection bias, different evaluation and statistical methods, and something else.

A body evidences showed that CD147 expression was positively related to the poor prognosis of the patients with urothelial carcinoma, pancreatic cancer, tongue squamous cell carcinoma, cervical squamous cell carcinoma, laryngeal carcinoma, and advanced renal cell carcinoma [53, 54, 61-64]. CD147 expression might be demonstrated to indicate the worse prognosis of HCC, thyroid cancer, glioma and esophageal squamous carcinoma as an independent factor $[55,58,65,66]$. $\mathrm{Xu}$ et al. [67] demonstrated that the patients with high CD147 expression and membranous localization predicted poor prognosis in both squamous cell carcinoma and adenocarcinoma. Here, meta-analysis showed that CD147 expression was positively linked to the worse prognosis of the patients with gastric cancer. Bioinformatics analysis indicated that CD147 mRNA expression was negatively associated with overall and progression-free survival rates of the patients with gastric cancer, even stratified by clinicopathological features. Taken together, CD147 expression might be considered as a potential marker for the prognosis of the patients with gastric cancer at either mRNA or protein level.

Recently, Hu et al. [68] has reported that CD147 overexpression may serve as a promising diagnostic and prognostic marker for gastric cancer using a meta- and immunohistochemical study. The differences between our and Hu's studies are summarized as follows: 1) We have clarified the clinicopathological and prognostic significances of CD147 protein expression as previously reported [21]. 2) We collected more articles from Pubmed, Web of Science, Biosis, Scifinder and CNKI than Hu et al. (22 vs 17); 3) The prognostic significance of CD147 protein expression was analyzed by extracting the survival data using Engauge Digitizer software for our metaanalysis. 4) Importantly, we performed bioinformatics analysis to explore the clinicoapthological and prognostic significances of CD147 mRNA expression using Oncomine, TCGA and KM plotter.

In conclusion, CD147 expression was up-regulated in gastric cancer, and positively correlated with advanced clinicopathological features and worse prognosis at both mRNA and protein levels. It might be employed as a good potential marker for carcinogenesis, aggressive behaviors and unfavorable prognosis of gastric cancer patients. However, the following limitations should be noted: (1) the potential publication bias stems from published results being predominantly positive; (2) patient populations in our study were limited, as patients came only from Asia and Brazil; (3) all of the survival data were extracted from survival curves, which may introduce subjective bias.

\section{MATERIALS AND METHODS}

\section{Identification of eligible studies and data extraction}

We performed a publication search using PubMed, Web of Science, BIOSIS and SciFinder updated on March 14, 2017. The following search terms were used: (CD147 OR EMMPRIN OR Basigin) AND (gastric OR stomach) AND (cancer OR carcinoma OR adenocarcinoma). Searching was done without restriction on language or publication years. Inclusion criteria for studies: (1) articles to observe the alteration in CD147 expression in gastric cancer by immunohistochemistry; (2) papers to compare CD147 expression with pathobiological behaviors and prognosis of gastric cancer by immunohistochemistry. Exclusion criteria included: (1) abstract, comment, review and meeting; (2) duplication of the previous publications; (3) Western blot, RT-PCR, cDNA microarray, or transcriptomic sequencing for CD147 expression; (4) lack of sufficient information. 


\section{Data extraction}

Based on the inclusion criteria, two reviewers (HC Zheng and BC Gong) independently extracted information from all eligible publications. The following information were included in each study: name of first author, year of publication, country, ethnicity, antibody company, numbers of cases and controls, expression alteration, and follow-up outcome. Regarding survival analysis, we used Engauge Digitizer software to extract data from KaplanMeier curves and calculated the Hazard ratios (HR) and their corresponding 95\% confidence intervals (CI). Any disagreement was resolved through discussion until the two reviewers reached a consensus.

\section{Quality score assessment}

Two reviewers (HC Zheng and BC Gong) independently assessed the quality of the included studies according to Newcastle Ottawa Scale (NOS) (http://www. ohri.ca/programs /clinical_ epidemiology/oxford.htm). The scale consists of three components related to sample selection, comparability and ascertainment of outcome.

\section{Bioinformatics analysis}

The individual gene expression level of $C D 147$ was analyzed using Oncomine (www. oncomine.org), a cancer microarray database and web-based data mining platform for a new discovery from genome-wide expression analyses. We compared the differences in CD147 mRNA level between gastric mucosa and cancer. All data were log-transformed, median centered per array, and standard deviation normalized to one per array. The expression (RNA-seqV2) and clinicopathological data of 392 gastric cancer patients were downloaded from the Cancer Genome Atlas (TCGA) database by TCGA-assembler in $\mathrm{R}$ software. We integrated the raw data, analyzed CD147 mRNA expression in gastric cancer, and compared it with clinicopathological and prognostic data of the patients with gastric cancer. Additionally, the prognostic significance of CD147 mRNA was also analyzed using Kaplan-Meier plotter (http://kmplot.com).

\section{Statistics analysis}

HWE was evaluated using Chi-square test in control groups of each study. Strength of association between CD147 expression and cancer risk was assessed by odds ratios with $95 \%$ confidence intervals. Statistical significance of the pooled OR was determined by $Z$ test. If there was no significant heterogeneity, the fixed effect model (Mantel-Haenszel method) would be employed. Otherwise, the random effect model (DerSimonian and Laird method) would be used excluding prognostic analysis. Heterogeneity effect was then quantified by $I^{2}$ test, which was subdivided into low, moderate and high degrees of heterogeneity according to the cut-off values of $25 \%, 50 \%$ and $75 \%$ respectively. Publication bias was evaluated by funnel plot and quantified by Begg's test and Egger's test to assess funnel plot asymmetry. Metaanalyses were performed with Revman software 5.3 and data from TCGA database was dealt with SPSS 10.0 software using student $t$ test. Kaplan-Meier survival plots were generated and comparisons between survival curves were made with the log-rank statistic. Two-sided $p<0.05$ was considered as statistically significant.

\section{ACKNOWLEDGMENTS AND FUNDING}

This study was supported by Liaoning BaiQianWan Talents Program, Award for Liaoning Distinguished Professor, a Key Scientific and Technological Project of Liaoning Province (2015408001) and National Natural Scientific Foundation of China $(81472544 ; 81672700)$.

\section{CONFLICTS OF INTEREST}

The authors have declared that no competing interests exist.

\section{REFERENCES}

1. Muramatsu T. Basigin (CD147), a multifunctional transmembrane glycoprotein with various binding partners. J Biochem. 2016; 159:481-490.

2. Grass GD, Dai L, Qin Z, Parsons C, Toole BP. CD147: regulator of hyaluronan signaling in invasiveness and chemoresistance.Adv Cancer Res. 2014; 123:351-373.

3. Bai Y, Huang W, Ma LT, Jiang JL, Chen ZN. Importance of $\mathrm{N}$-glycosylation on CD147 for its biological functions. Int J Mol Sci. 2014; 15:6356-6377.

4. Wang WJ, Li QQ, Xu JD, Cao XX, Li HX, Tang F, Chen Q, Yang JM, Xu ZD, Liu XP. Interaction between CD147 and P-glycoprotein and their regulation by ubiquitination in breast cancer cells. Chemotherapy. 2008; 54:291-301.

5. Wu B, Liu ZY, Cui J, Yang XM, Jing L, Zhou Y, Chen ZN, Jiang JL.F-Box Protein FBXO22 Mediates Polyubiquitination and Degradation of CD147 to Reverse Cisplatin Resistance of Tumor Cells. Int J Mol Sci. $2017 ; 18$.

6. Jia L, Zhou H, Wang S, Cao J, Wei W, Zhang J. Deglycosylation of CD147 down-regulates Matrix Metalloproteinase-11 expression and the adhesive capability of murine hepatocarcinoma cell HcaF in vitro. IUBMB Life. 2006; 58:209-216.

7. Zhao Y, Chen S, Gou WF, Niu ZF, Zhao S, Xiao LJ, Takano Y, Zheng HC. The role of EMMPRIN expression in ovarian epithelial carcinomas. Cell Cycle. 2013; 12:2899-2913. 
8. Egawa N, Koshikawa N, Tomari T, Nabeshima K, Isobe T, Seiki M. Membrane type 1 matrix metalloproteinase (MT1MMP/MMP-14) cleaves and releases a 22-kDa extracellular matrix metalloproteinase inducer (EMMPRIN) fragment from tumor cells. J Biol Chem. 2006; 281:37576-37585.

9. Bhagirath D, Abrol N, Khan R, Sharma M, Seth A, Sharma A. Expression of CD147, BIGH3 and Stathmin and their potential role as diagnostic marker in patients with urothelial carcinoma of the bladder. Clin Chim Acta. 2012; 413:1641-1646.

10. Bilgin Doğru E, Dizdar Y, Akşit E, Ural F, Şanlı Ö, Yasasever V. EMMPRIN and ADAM12 in prostate cancer: preliminary results of a prospective study. Tumour Biol. 2014; 35:11647-11653.

11. Xu T, Zhou M, Peng L, Kong S, Miao R, Shi Y, Sheng H, Li L. Upregulation of CD147 promotes cell invasion, epithelial-to-mesenchymal transition and activates MAPK/ ERK signaling pathway in colorectal cancer. Int J Clin Exp Pathol. 2014; 7:7432-7441.

12. Wu J, Ru NY, Zhang Y, Li Y, Wei D, Ren Z, Huang XF, Chen ZN, Bian H. HAb18G/CD147 promotes epithelialmesenchymal transition through TGF- $\beta$ signaling and is transcriptionally regulated by Slug. Oncogene. 2011; 30:4410-4427.

13. Ru NY, Wu J, Chen ZN, Bian H. HAb18G/CD147 is involved in TGF- $\beta$-induced epithelial- mesenchymal transition and hepatocellular carcinoma invasion. Cell Biol Int. 2015; 39:44-51.

14. Wu J, Lu M, Li Y, Shang YK, Wang SJ, Meng Y, Wang Z, Li ZS, Chen H, Chen ZN, Bian H. Regulation of a TGF$\beta 1-C D 147$ self-sustaining network in the differentiation plasticity of hepatocellular carcinoma cells. Oncogene. 2016; 35:5468-5479.

15. Zhou S, Liao L, Chen C, Zeng W, Liu S, Su J, Zhao S, Chen M, Kuang Y, Chen X, Li J. CD147 mediates chemoresistance in breast cancer via ABCG2 by affecting its cellular localization and dimerization. Cancer Lett. 2013; 337:285-292.

16. Lv Y, Wang T, Fan J, Zhang Z, Zhang J, Xu C, Li Y, Zhao G, He C, Meng H, Yang H, Wang Z, Liu J, et al. The effects and mechanisms of SLC34A2 on maintaining stem cell- like phenotypes in CD147+ breast cancer stem cells. Tumour Biol. 2017; 39:1010428317 695927.

17. Xin X, Zeng X, Gu H, Li M, Tan H, Jin Z, Hua T, Shi R, Wang H. CD147/EMMPRIN overexpression and prognosis in cancer: A systematic review and meta-analysis. Sci Rep. 2016; 6:32804.

18. Liang YX, Mo RJ, He HC, Chen JH, Zou J, Han ZD, Lu JM, Cai C, Zeng YR, Zhong WD, Wu CL. Aberrant hypomethylation-mediated CD147 overexpression promotes aggressive tumor progression in human prostate cancer. Oncol Rep. 2015; 33:2648-2654.

19. Kong LM, Liao CG, Chen L, Yang HS, Zhang SH, Zhang Z, Bian HJ, Xing JL, Chen ZN. Promoter hypomethylation upregulates CD147 expression through increasing Sp1 binding and associates with poor prognosis in human hepatocellular carcinoma. J Cell Mol Med. 2011; 15:1415-1428.

20. Wang B, Xu YF, He BS, Pan YQ, Zhang LR, Zhu C, Qu LL, Wang SK. RNAi-mediated silencing of CD147 inhibits tumor cell proliferation, invasion and increases chemosensitivity to cisplatin in SGC7901 cells in vitro. J Exp Clin Cancer Res. 2010; 29:61.

21. Zheng HC, Takahashi H, Murai Y, Cui ZG, Nomoto K, Miwa S, Tsuneyama K, Takano Y. Upregulated EMMPRIN/ CD147 might contribute to growth and angiogenesis of gastric carcinoma: a good marker for local invasion and prognosis. Br J Cancer. 2006; 95:1371-1378.

22. Chen T, Xie LM, Zhou XT. The expression alteration and significance of CD147 and intergrin $\alpha 3$ in gastric cancer. Shandong Yiyao. 2013; 53:33-34.

23. Chen ZQ, Wang H, Zhang QA, Li Q, Xu ZD. Expression of MT1, MMP, EMMPRIN, p-gp in gastri carcinoma and their correlation. China Oncol. 2005:15:113-116.

24. Chu D, Zhu S, Li J, Ji G, Wang W, Wu G, Zheng J. CD147 expression in human gastric cancer is associated with tumor recurrence and prognosis. PLoS One. 2014 30; 9:e101027.

25. Fan RG, Ling L, Cha M, Dai M. Expression and significance of EMMRPIN and MMP-9 in gastric cancer. Chin J Gen Prac. 2010; 18:977-979.

26. Gao J, Chen HL, Xue JL, Zhu RQ. Correlation of the expression of EMMPRIN and HER-2 proteins with invasiveness and metastasis of human gastric carcinoma. Shijie Huaren Xiaohua Zazhi. 2009; 17:1952-1956.

27. Gao WH, Fu Y, Lu N. The expression of CD147, CEA and their prognostic value in gastric cancer. Mod Oncol. 2016; 24:2750-2754.

28. He C, Zhong Y, Chen J. Expression and significance of CD147 and MMPs in gastric carcinoma. Shandong Yiyao. 2009; 49:12-13.

29. Huang L, Xu AM, Peng Q. CD147 and MMP-9 expressions in type II/III adenocarcinoma of esophagogastric junction and their clinicopathological significances. Int J Clin Exp Pathol. 2015; 8:1929-1937.

30. Huang Y, Zhao JH, Fan KW. The expression of significance of matrix metalloproteinase -2 and CD147 in gastric carcinoma. J Bas Clin Oncol. 2007; 20:21-23.

31. Li B, Luo LL, Lai DN. Expression and significance of S100P, CD147 and OCT4 in different stages of TNM of gastric cancer. Hebei Med J. 2016; 38:492-495.

32. Liu L, Guo L, Wang ZW, Ji J, Zhang JN, Yan M, Liu BY, Zhu ZG, Yu YY. Expression of Hab18G/CD147 in large sample of gastric cancer tissue specimen. J Diag Concept Pract. 2012; 11:42-46.

33. Liu XL, Chen HL, Yu BP, Guo MW, Li L. Significance of expression of EMMPRIN and MT1-MMPP in primary gastric carcinoma and associated lymph node metastases. Shijie Huaran Xiaohua Zazhi. 2012; 20:27-33.

34. Miao J. Expression of HER-2, MT1-MMP and CD147 in gastric carcinoma and their significances. J Clin Exp Pathol. 2012; 1361-1364. 
35. Pinheiro C, Longatto-Filho A, Simões K, Jacob CE, Bresciani CJ, Zilberstein B, Cecconello I, Alves VA, Schmitt F, Baltazar F. The prognostic value of CD147/ EMMPRIN is associated with monocarboxylate transporter 1 co-expression in gastric cancer. Eur J Cancer. 2009; 45:2418-2424.

36. Wu Q, Zhang H, Zhang HP. Investigation of CD147 and MMP-2 expression in gastric carcinoma and their significance by tissue microarray. J Anhui Med Univ. 2010; 45:43-46.

37. Xu JM, Dong T, Tian XP, Chen J, Wang M. Expression of PTEN and CD147 and AKT2 in gastric carcinoma tissues and the clinical significance. Chin J Curr Adv Gen Surg. 2010; 13:681-684.

38. Zhang LT, Bao ZY. Expression of CD147 and MMP-9 in gastric cancer and its significance. Yixue Zongshu. 2013; 19:163-165.

39. Zhou JF, Shen QX. Expression levels and clinical significance of CD147 and S100P in gastric cancer tissue. Mod J Integ Trad Chin West Med. 2016; 25:973-975.

40. Zhou MX, Xiao H. The correlation between CD147 and HER-2 expression and invasion and metastasis of gastric cancer. J Clin Exp Pathol. 2013; 29:1250-1252.

41. Zheng HC, Li XH, Hara T, Masuda S, Yang XH, Guan YF, Takano Y. Mixed-type gastric carcinomas exhibit more aggressive features and indicate the histogenesis of carcinomas. Virchows Arch. 2008; 452:525-534.

42. Zheng X, Ma H, Wu QH, Huang YD, Wu J. Expression of CD147 in gastric carcinoma and its clinical significance. Chin J Cancer Prev Treat. 2005; 12:1385-1387.

43. Xu BQ, Fu ZG, Meng Y, Wu XQ, Wu B, Xu L, Jiang JL, Li L, Chen ZN. Gemcitabine enhances cell invasion via activating HAb18G/CD147-EGFR-pSTAT3 signaling. Oncotarget. 2016; 7:62177-62193. https://doi.org/10.18632/ oncotarget.11405.

44. Cui HY, Wang SJ, Miao JY, Fu ZG, Feng F, Wu J, Yang XM, Chen ZN, Jiang JL. CD147 regulates cancer migration via direct interaction with Annexin A2 and DOCK3- $\beta$-cateninWAVE2 signaling. Oncotarget. 2016; 7:5613-5629. https:// doi.org/10.18632/oncotarget.6723.

45. Wang SJ, Cui HY, Liu YM, Zhao P, Zhang Y, Fu ZG, Chen ZN, Jiang JL. CD147 promotes Src-dependent activation of Rac1 signaling through STAT3/DOCK8 during the motility of hepatocellular carcinoma cells. Oncotarget. 2015; 6:243-257. https://doi.org/10.18632/oncotarget.2801.

46. Zhao P, Zhang W, Wang SJ, Yu XL, Tang J, Huang W, Li Y, Cui HY, Guo YS, Tavernier J, Zhang SH, Jiang JL, Chen ZN. HAb18G/CD147 promotes cell motility by regulating annexin II-activated RhoA and Rac1 signaling pathways in hepatocellular carcinoma cells. Hepatology. 2011; 54:2012-2024.

47. Sidhu SS, Nawroth R, Retz M, Lemjabbar-Alaoui H, Dasari V, Basbaum C. EMMPRIN regulates the canonical Wnt/betacatenin signaling pathway, a potential role in accelerating lung tumorigenesis.Oncogene. 2010; 29:4145-4156.
48. Su J, Gao T, Jiang M, Wu L, Zeng W, Zhao S, Peng C, Chen X. CD147 silencing inhibits tumor growth by suppressing glucose transport in melanoma. Oncotarget. 2016; 7:64778-64784. https://doi.org/10.18632/ oncotarget.11415.

49. Ren YX, Wang SJ, Fan JH, Sun SJ, Li X, Padhiar AA, Zhang JN. CD147 stimulates hepatoma cells escaping from immune surveillance of $\mathrm{T}$ cells by interaction with Cyclophilin A. Biomed Pharmacother. 2016; 80:289-297.

50. Li J, Huang Q, Long X, Zhang J, Huang X, Aa J, Yang H, Chen Z, Xing J. CD147 reprograms fatty acid metabolism in hepatocellular carcinoma cells through Akt/mTOR/ SREBP1c and P38/PPAR $\alpha$ pathways. J Hepatol. 2015; 63:1378-1389.

51. Fang F, Wang L, Zhang S, Fang Q, Hao F, Sun Y, Zhao L, Chen S, Liao H, Wang L.CD147 modulates autophagy through the PI3K/Akt/mTOR pathway in human prostate cancer PC-3 cells. Oncol Lett. 2015; 9:1439-1443.

52. Ma C, Wang J, Fan L, Guo Y.Inhibition of CD147 expression promotes chemosensitivity in HNSCC cells by deactivating MAPK/ERK signaling pathway. Exp Mol Pathol. 2017; 102:59-64.

53. Huhe M, Liu S, Zhang Y, Zhang Z, Chen Z. Expression levels of transcription factors c-Fos and c-Jun and transmembrane protein HAb18G/CD147 in urothelial carcinoma of the bladder. Mol Med Rep. 2017; 15:2991-3000.

54. Gou X, Chen H, Jin F, Wu W, Li Y, Long J, Gong X, Luo M, Bi T, Li Z, He Q.Expressions of CD147, MMP-2 and MMP9 in laryngeal carcinoma and its correlation with poor prognosis. Pathol Oncol Res. 2014; 20:475-81.

55. Tan H, Ye K, Wang Z, Tang H. CD147 expression as a significant prognostic factor in differentiated thyroid carcinoma. Transl Res. 2008; 152:143-149.

56. Zheng HC, Wang W, Xu XY, Xia P, Yu M, Sugiyama T, Takano Y.Up-regulated EMMPRIN/CD147 protein expression might play a role in colorectal carcinogenesis and its subsequent progression without an alteration of its glycosylation and mRNA level.J Cancer Res Clin Oncol. 2011; 137:585-596.

57. Zhao Y, Chen S, Gou WF, Niu ZF, Zhao S, Xiao LJ, Takano Y, Zheng HC.The role of EMMPRIN expression in ovarian epithelial carcinomas. Cell Cycle. 2013; 12:2899-2913.

58. Tian L, Zhang Y, Chen Y, Cai M, Dong H, Xiong L. EMMPRIN is an independent negative prognostic factor for patients with astrocytic glioma. PLoS One. 2013; 8:e58069.

59. Huang Z, Huang H, Li H, Chen W, Pan C.EMMPRIN expression in tongue squamous cell carcinoma. J Oral Pathol Med. 2009; 38:518-523.

60. Zhu S, Li Y, Zhang Y, Wang X, Gong L, Han X, Yao L, Lan M, Zhang W. Expression and clinical implications of HAb18G/CD147 in hepatocellular carcinoma. Hepatol Res. 2015; 45:97-106.

61. Kaira K, Arakawa K, Shimizu K, Oriuchi N, Nagamori S, Kanai Y, Oyama T, Takeyoshi I. Relationship between 
CD147 and expression of amino acid transporters (LAT1 and ASCT2) in patients with pancreatic cancer. Am J Trans1 Res. 2015; 7:356-363.

62. Yu YH, Morales J, Feng L, Lee JJ, El-Naggar AK, Vigneswaran N. CD147 and Ki-67 overexpression confers poor prognosis in squamous cell carcinoma of oral tongue: a tissue microarray study. Oral Surg Oral Med Oral Pathol Oral Radiol. 2015; 119:553-565.

63. Huang XQ, Chen X, Xie XX, Zhou Q, Li K, Li S, Shen LF, $\mathrm{Su}$ J. Co-expression of CD147 and GLUT-1 indicates radiation resistance and poor prognosis in cervical squamous cell carcinoma. Int J Clin Exp Pathol. 2014; 7:1651-1666.

64. Liang YX, He HC, Han ZD, Bi XC, Dai QS, Ye YK, Qin WJ, Zeng GH, Zhu G, Xu CL, Zhong WD. CD147 and VEGF expression in advanced renal cell carcinoma and their prognostic value. Cancer Invest. 2009 8; 27:788-793.

65. Zhang Q, Chen X, Zhou J, Zhang L, Zhao Q, Chen G, Xu J, Qian F, Chen Z. CD147, MMP-2, MMP-9 and MVDCD34 are significant predictors of recurrence after liver transplantation in hepatocellular carcinoma patients.Cancer Biol Ther. 2006; 5:808-814.
66. Zhu S, Li Y, Mi L, Zhang Y, Zhang L, Gong L, Han X, Yao L, Lan M, Chen Z, Zhang W. Clinical impact of HAb18G/CD147 expression in esophageal squamous cell carcinoma. Dig Dis Sci. 2011; 56:3569-3576.

67. Xu XY, Lin N, Li YM, Zhi C, Shen H. Expression of HAb18G/CD147 and its localization correlate with the progression and poor prognosis of non-small cell lung cancer. Pathol Res Pract. 2013; 209:345-352.

68. Hu C, Dong X, Wu J, Xiao F, Shang J, Liu L, Yang Y, Luo D, Li Q, Song Q, Yang J, Zhang C, Shen L, et al. CD147 overexpression may serve as a promising diagnostic and prognostic marker for gastric cancer: evidence from original research and literature. Oncotarget. 2017; 8:3088830899. https://doi.org/10.18632/oncotarget.15737. 